\title{
Study on Effect of Intermittent Exposure to Extremely Low Frequency Magnetic Fields on Development of Zebrafish Embryos
}

\author{
Liu Zhenhuan, Liu Xinfa, Xie Huichun, Zhang Jiangong, LuYao \\ China Electric Power Research Institute, Wuhan 430074,China
}

\begin{abstract}
In order to investigate the effects of intermittent exposure extremely low frequency magnetic field on embryonic development of fish, Zebrafish was selected to serve as the study object to study the embryonic development effect of intermittent exposure to magnetic fields. Hatching fertilized eggs of zebrafish was placed in the magnetic field of $50 \mathrm{~Hz}$ and $100 \mu \mathrm{T}$, and divided into five groups which include control group, " $1 \mathrm{~h}$ exposure/5h intermittence", "2h exposure/4h intermittence”, “3h exposure/3h intermittence” and full day exposure according to daily exposure time. Then, it was necessary to analyze the difference between relevant embryonic development indexes of each group. The results showed that at $96 \mathrm{~h}$ of zebrafish embryonic development, there was no significant difference between survival rate, aberration rate, hatching rate of exposed embryos in each magnetic field and the control group (probability $\mathrm{P}>0.05$ ); Heart rate gradually increased with the increase of embryo and there were no significant differences between groups $(\mathrm{P}>0.05)$. The study showed that the selected magnetic field exposure conditions had no significant effect on embryonic development of fish.
\end{abstract}

Keywords: extremely low frequency magnetic field; intermittent exposure; zebrafish; embryonic development; death rate; aberration rate; hatching rate; heart rate

\section{Introduction}

The living organism is always affected by the environmental factors, which include extremely low frequency magnetic fields (ELF-MF). ELF-MF in the environment is from many aspects, such as domestic appliances, high-speed trains, hydroelectric generation, power transmission or power distribution through power lines and cables, usage of electrical facilities and high-voltage transmission lines and others. Along with the scientific and technological development and continuous improvement of human living standard, human and other creatures are always exposed to ELF-MF, so the potential biological effect gets extensive attention ${ }^{[1]}$.

Biological effect of magnetic field is the objective existence, and the main influence factors include magnetic field factors and biological factors. Among 
them, magnetic factors include magnetic field type, frequency, intensity and exposure time etc; biological factors include species, age and other functional status of tested organisms and others ${ }^{[1]}$. Due to the difference of magnetic field exposure parameters, study object and biological effect parameters and others, results of numerous researches on biological effects of magnetic fields are not consistent and there are many disputes.

World health organization recommends using ICNIRP Guidelines for Limiting Exposure to Time-varying Electric, Magnetic and Electromagnetic Fields (up to 300GHz) (referred to as ICNIRP Guidelines (1998)) as magnetic field exposure standards which is established according to identified health effect, considers the magnetic field effect of human and other animals, and stipulates that exposure limit value of $50 \mathrm{~Hz}$ magnetic field is $100 \mu \mathrm{T}$. According to our electromagnetic environmental management practice, exposure limit value stipulated in Limits for Controlling Public Exposure in Electromagnetic Environment is same as ICNIRP Guidelines (1998) which is $100 \mu \mathrm{T}$. Fish is the typical species of aquatic organism with great research significance for biological effects of magnetic fields.

There is relatively obvious stress of early embryonic development on environment. Research of Lotfi and others found that $50 \mathrm{~Hz}$ and $500 \mu \mathrm{T}$ magnetic fields can induce reduction of chicken embryonic hatching rate and increase of death rate; research of Zimmerman and others indicated that for $23 \mathrm{~h}$ exposure of sea urchin embryos to $50 \mathrm{~Hz}$ and $100 \mu \mathrm{T}$ magnetic fields, exposure group had $1 \mathrm{~h}$ embryonic development delay in blastula stage. Similar research indicated that trout and rainbow trout had embryonic development delay and increase of heart rhythm and respiration intensity when exposed in 1-13 mT magnetic fields. At the same time, studies have found that there is different influence of different exposure time on creatures. When fish embryos were exposed to $1 \mathrm{mT}$ power frequency magnetic field after respectively after $2 \mathrm{~h}$ and $48 \mathrm{~h}$ of fertilization by Skauli and others, they found that there was no effect on embryonic development of fish in magnetic field exposure with $2 \mathrm{~h}$ of fertilization, but there was delay in embryonic development of fish in magnetic field exposure with $48 \mathrm{~h}$ of fertilization. There was different effect of quail embryos' intermittent exposure to $1 \mathrm{mT}$ power frequency magnetic field for different time on its vascular development. Embryonic vessel formation of " $2 \mathrm{~h}$ exposure/ $6 \mathrm{~h}$ intermittence" and " $3 \mathrm{~h}$ exposure/ $5 \mathrm{~h}$ intermittence" exposure groups was restrained and there is no significant difference between other groups and the control group, which showed the "time window" effect of exposure to magnetic field ${ }^{[3]}$.

In order to examine the rationality of magnetic field exposure limit value $(100 \mu \mathrm{T})$, considering time which is the biological impact factor of magnetic field exposure, zebrafish which is a kind of model vertebrate was selected in this paper to study the effect of ELF-MF intermittent exposure with $50 \mathrm{~Hz}$ and $100 \mu \mathrm{T}$ on embryonic development of zebrafish with the aim of further defining the embryonic biological effect of ELF-MF and providing scientific basis for determining the safety threshold of ELF-MF exposure creatures and discussing the biological effect mechanism. 


\section{Materials and Methods}

\subsection{Experimental fish and embryo}

Pubescent zebrafish (Danio rerio) was raised in flowing water aquaculture system (institute of hydrobiology, Chinese academy of sciences, Wuhan) whose water temperature was $(28 \pm 0.5){ }^{\circ} \mathrm{C}$ and illumination/darkness period was within $14 \mathrm{~h} / 10 \mathrm{~h}$ with male and female zebrafish in different cylinder. Before the experiment, female and male zebrafish was matched as 1:2 for natural mating and egg-laying. Fertilized egg was selected for exposure experiment.

\subsection{Experimental magnetic field}

Magnetic field exposure equipment is designed and developed by ourselves which is composed of voltage regulator and Helmholtz coils. Helmholtz coils are two groups of $1 \mathrm{~m} \times 1 \mathrm{~m}$ square coils which are placed relatively up and down to produce axial magnetic field. Each group of coils includes 100 turns of $1.5 \mathrm{~mm}$ enameled copper wires, as shown in Figure 1-9. Through transformer, $50 \mathrm{~Hz}$ alternating current produced relatively uniform $50 \mathrm{~Hz}$ magnetic field in Helmholtz coils. Voltage regulator was adjusted to magnetic field intensity of $100 \mu \mathrm{T}$. Magnetic field intensity was measured by HI-3604 measuring instrument of power frequency electromagnetic field. The experiment was conducted in temperature control laboratory. Among them, background magnetic field intensity of the laboratory was $0.13 \pm 0.02 \mu \mathrm{T}^{[4]}$.

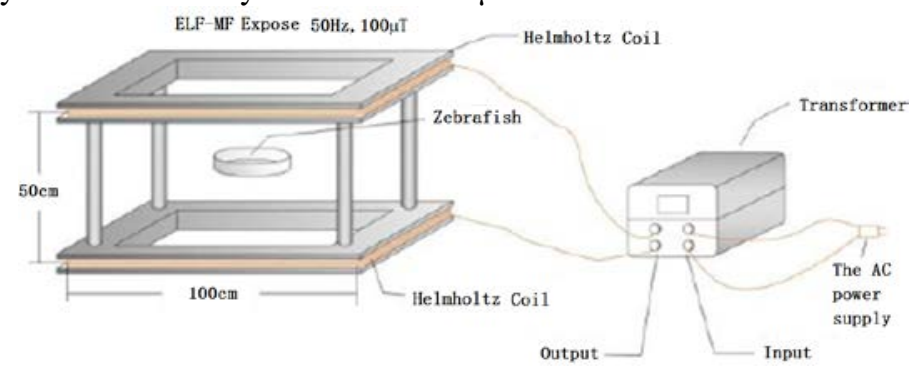

Figure 1 ELF-MFs exposure apparatus of zebrafish

\subsection{Grouping of experiments}

Fertilized eggs of zebrafish were randomly divided into the control group and four exposure groups in magnetic fields. Each group was set with three parallel control groups which included 100 fertilized eggs. Exposure time in the magnetic field was up to $96 \mathrm{~h}$ of embryonic development. According to exposure time, magnetic field exposure groups were divided into four groups which included " $1 \mathrm{~h}$ exposure/5h intermittence", " $2 \mathrm{~h}$ exposure/4 h intermittence", "3 h exposure/3 h intermittence” and full day exposure, as shown in Table 1.

Table 1 Magnetic field exposure program of each group

\begin{tabular}{|l|l|l|l|l|} 
Group & Each Exposure & Each Interval h & Daily & Total Exposure \\
\hline
\end{tabular}




\begin{tabular}{|c|c|c|c|c|}
\hline & Time h & & $\begin{array}{c}\text { Exposure Time } \\
\mathrm{h}\end{array}$ & Time h \\
\hline Control Group & - & - & 0 & 0 \\
\hline $\begin{array}{c}\text { Experiment } \\
\text { Group 1 }\end{array}$ & 1 & 5 & 4 & 16 \\
\hline $\begin{array}{c}\text { Experiment } \\
\text { Group 2 }\end{array}$ & 2 & 4 & 8 & 32 \\
\hline $\begin{array}{c}\text { Experiment } \\
\text { Group 3 }\end{array}$ & 3 & 3 & 12 & 48 \\
\hline $\begin{array}{c}\text { Experiment } \\
\text { Group 4 }\end{array}$ & - & - & 24 & 96 \\
\hline
\end{tabular}

\subsection{Death rate detection}

In the experimental process, it was required to record the embryonic death conditions of control group at 24h, 48h and 96h of zebrafish embryonic development and four experimental groups.

\subsection{Aberration rate detection}

In the exposure experiment, embryonic aberration rate of zebrafish in five experimental groups was recorded when embryonic development of zebrafish was up to $96 \mathrm{~h}$.

\subsection{Hatching rate detection}

The membrane embryonic number of each experimental group was respectively recorded at $48 \mathrm{~h}, 60 \mathrm{~h}, 72 \mathrm{~h}$ and $96 \mathrm{~h}$ of zebrafish embryonic exposure to magnetic field.

\subsection{Heart rate detection}

At 36h, 48h, 60h and $72 \mathrm{~h}$ of exposure in magnetic field, 6 embryos were randomly selected from each parallel group to be observed under anatomical lens and record the heart rate of zebrafish for each $15 \mathrm{~s}$.

\subsection{Statistical analysis}

Experimental data was shown in average value \pm standard deviation (SEM) and applied with SPSS 17.0 statistical software for variance analysis (ANOVA). Later, each group was applied with LSD for inspection and $\mathrm{P}<0.05$ was regarded as measuring standard for significant difference.

\section{Results}




\subsection{Embryonic death rate}

Under the condition of magnetic field exposure, compared with the control group, there was no significant difference between experiment group 1, 2 and 3 at $24 \mathrm{~h}, 48 \mathrm{~h}$ and $96 \mathrm{~h}$ of embryonic development. The death rate of experiment group 4 was slightly higher than the control group, but without statistical difference ( $\mathrm{P}>0.05$, see Table 2$)$.

Table 2 Comparison of zebrafish embryonic death rate in magnetic

field exposure at different time

\begin{tabular}{|c|c|c|c|c|c|}
\hline Time h & $\begin{array}{c}\text { Control } \\
\text { Group }\end{array}$ & $\begin{array}{c}\text { Experiment } \\
\text { Group 1 }\end{array}$ & $\begin{array}{c}\text { Experiment } \\
\text { Group 2 }\end{array}$ & $\begin{array}{c}\text { Experiment } \\
\text { Group 3 }\end{array}$ & $\begin{array}{c}\text { Experiment } \\
\text { Group 4 }\end{array}$ \\
\hline 24 & $7.03 \pm 0.75$ & $7.04 \pm 0.20$ & $7.42 \pm 0.50$ & $7.72 \pm 1.38$ & $8.08 \pm 0.29$ \\
\hline 48 & $10.43 \pm 0.56$ & $10.22 \pm 0.79$ & $10.92 \pm 0.52$ & $10.78 \pm 0.31$ & $11.37 \pm 2.26$ \\
\hline 96 & $15.45 \pm 1.30$ & $14.94 \pm 1.18$ & $15.14 \pm 2.35$ & $14.96 \pm 2.71$ & $17.05 \pm 0.70$ \\
\hline
\end{tabular}

\subsection{Embryonic aberration rate}

Under the condition of magnetic field exposure, at 96h of embryonic development, compared with the control group, embryonic aberration rate of four experimental groups was slightly higher than the control group, but without statistical difference ( $\mathrm{P}>0.05$, see Table 3 ).

Table 3 Comparison of zebrafish embryonic aberration rate in magnetic field exposure at different time

\begin{tabular}{|c|c|c|c|c|c|}
\hline Time h & $\begin{array}{c}\text { Control } \\
\text { Group }\end{array}$ & $\begin{array}{c}\text { Experiment } \\
\text { Group 1 }\end{array}$ & $\begin{array}{c}\text { Experiment } \\
\text { Group 2 }\end{array}$ & $\begin{array}{c}\text { Experiment } \\
\text { Group 3 }\end{array}$ & $\begin{array}{c}\text { Experiment } \\
\text { Group 4 }\end{array}$ \\
\hline 96 & $3.05 \pm 0.51$ & $3.28 \pm 0.40$ & $3.19 \pm 0.26$ & $3.44 \pm 0.28$ & $3.39 \pm 0.35$ \\
\hline
\end{tabular}

\subsection{Embryonic hatching rate}

Under the conditions of magnetic field exposure, at $48 \mathrm{~h}, 54 \mathrm{~h}, 60 \mathrm{~h}, 72 \mathrm{~h}$ and 96h of embryonic development, compared with the control group, embryonic hatching rate of four experimental groups was slightly lower than the control group, but without statistical difference ( $\mathrm{P}>0.05$, see Table 4$)$.

Table 4 Comparison of zebrafish embryonic hatching rate in magnetic field exposure at different time

\begin{tabular}{|c|c|c|c|c|c|}
\hline Time h & $\begin{array}{c}\text { Control } \\
\text { Group }\end{array}$ & $\begin{array}{c}\text { Experiment } \\
\text { Group 1 }\end{array}$ & $\begin{array}{c}\text { Experiment } \\
\text { Group 2 }\end{array}$ & $\begin{array}{c}\text { Experiment } \\
\text { Group 3 }\end{array}$ & $\begin{array}{c}\text { Experiment } \\
\text { Group 4 }\end{array}$ \\
\hline 48 & $5.8 \pm 0.1$ & $4.4 \pm 0.4$ & $5.5 \pm 0.1$ & $4.7 \pm 0.6$ & $5.3 \pm 0.5$ \\
\hline 54 & $37.8 \pm 1.4$ & $35.5 \pm 1.8$ & $35.9 \pm 5.4$ & $35.8 \pm 2.8$ & $33.7 \pm 2.4$ \\
\hline 60 & $82.1 \pm 3.1$ & $82.1 \pm 0.1$ & $78.1 \pm 6.3$ & $81.3 \pm 2.6$ & $82.1 \pm 2.3$ \\
\hline 72 & $85.2 \pm 1.3$ & $85.9 \pm 0.5$ & $84.5 \pm 3.6$ & $84.4 \pm 2.7$ & $83.4 \pm 0.1$ \\
\hline
\end{tabular}




\begin{tabular}{|l|c|c|c|c|c|}
\hline 96 & $86.8 \pm 1.1$ & $86.3 \pm 0.9$ & $85.0 \pm 2.1$ & $84.7 \pm 2.3$ & $84.0 \pm 2.0$ \\
\hline
\end{tabular}

\subsection{Embryonic heart rate}

Under the conditions of magnetic field exposure, at 36h, 48h and 60h of embryonic development, compared with the control group, embryonic heart rate of four experimental groups was slightly lower than the control group, but without statistical difference; there was no significant difference between heart rate of experiment group and the control group ( $\mathrm{P}>0.05$, see Table 5 ) at $72 \mathrm{~h}$ of embryonic development.

Table 5 Comparison of zebrafish embryonic heart rate in magnetic field exposure at different time

\begin{tabular}{|c|c|c|c|c|c|}
\hline Time h & $\begin{array}{c}\text { Control } \\
\text { Group }\end{array}$ & $\begin{array}{c}\text { Experiment } \\
\text { Group 1 }\end{array}$ & $\begin{array}{c}\text { Experiment } \\
\text { Group 2 }\end{array}$ & $\begin{array}{c}\text { Experiment } \\
\text { Group 3 }\end{array}$ & $\begin{array}{c}\text { Experiment } \\
\text { Group 4 }\end{array}$ \\
\hline 36 & $36.8 \pm 1.2$ & $36.2 \pm 2.1$ & $36.8 \pm 1.6$ & $35.8 \pm 1.6$ & $36.2 \pm 1.2$ \\
\hline 48 & $41.0 \pm 1.4$ & $40.3 \pm 1.4$ & $40.2 \pm 0.7$ & $38.7 \pm 0.9$ & $39.5 \pm 0.2$ \\
\hline 60 & $47.3 \pm 1.4$ & $47.0 \pm 0.5$ & $45.8 \pm 2.1$ & $44.5 \pm 0.7$ & $45.3 \pm 2.8$ \\
\hline 72 & $48.0 \pm 0.9$ & $48.7 \pm 0.9$ & $46.7 \pm 1.9$ & $48.3 \pm 1.4$ & $47.2 \pm 1.6$ \\
\hline
\end{tabular}

\section{Discussions}

International agency for research on cancer classifies ELF-MF as suspicious carcinogen, but Electromagnetic Field and Public Health: Extremely Low Frequency Field Exposure (Fact Sheet No.322) and Environmental Health Criterion of Extremely Low Frequency Field (EHC No.238) officially released by world health organization (WHO) in 2007 conducts health risk evaluation on the effect of ELF-MF on creatures, and considers that there is yet not enough evidence for the effect of ELF-MF on many aspects and it is required to further study ELF-MF exposure biological effect and its mechanism. Due to indispensability of electricity, ELF-MF as a kind of ecological physical factor is everywhere in the everyday environment. The effects and applications of ELF-MF on human and other creatures get extensive attention at home and abroad.

Exposure time is an important factor affecting the biological effect of magnetic field. According to exposure time, Costa and others exposed quails to $60 \mathrm{~Hz}$ and $1 \mathrm{mT}$ magnetic field which included six groups as the control group, "1 h exposure/ $7 \mathrm{~h}$ intermittence", " $2 \mathrm{~h}$ exposure/ $6 \mathrm{~h}$ intermittence", " $3 \mathrm{~h}$ exposure/ 5 h intermittence”, " 4 h exposure/ 4 h intermittence” and " $24 \mathrm{~h}$ full day exposure". Results showed that embryonic vascularization of " 2 h exposure/ $6 \mathrm{~h}$ intermittence" and " $3 \mathrm{~h}$ exposure/ $5 \mathrm{~h}$ intermittence" exposed groups was restrained and there was no significant difference between other groups and the control group, thus showing "time window" effect of magnetic field exposure. Similarly, Sabine and others exposed human fibroblast to $50 \mathrm{~Hz}$ and $1 \mathrm{mT}$ magnetic fields according to many experimental groups which included "5 min/ 
5min”, “5 min/ $10 \mathrm{~min}$ ”, “5 min/ 15min”, “5 min/ $20 \mathrm{~min}$ ”, “5 min/ 25min”; and “1 min/ $10 \mathrm{~min}$ ”, “3 min/ $10 \mathrm{~min}$ ”, “5 min/ $10 \mathrm{~min}$ ”, “10 min/ $10 \mathrm{~min}$, “15 min/ $10 \mathrm{~min}$ " and "25 min/ $10 \mathrm{~min}$ " by the mode of "exposure/intermittence". They found that apart from four exposure groups of " $5 \mathrm{~min} / 20 \mathrm{~min}$ ", “ $5 \mathrm{~min} / 25 \mathrm{~min}$ ”, "1 $\mathrm{min} / 10 \mathrm{~min}$ ” and " $25 \mathrm{~min} / 10 \mathrm{~min}$ ”, cells of other experimental groups had significant cell DNA strand breakage, and the largest effect existed in exposure group of "5 $\mathrm{min} / 10 \mathrm{~min}$ ". Above research showed that there was certain relationship between biological effect of magnetic field and exposure time. However, in this experiment, under magnetic field $(50 \mathrm{~Hz}, 100 \mu \mathrm{T})$ exposure conditions of different intermittence, there was no obvious difference between various growth and development indexes in the development process of zebrafish. The manifestation was that there was no obvious effect of magnetic field on embryonic development of zebrafish. The difference with other study results may derives from the difference of exposure parameters, exposure time and species and others ${ }^{[5]}$.

Magnetic field parameters and exposure modes are important factor in studying the biological effect of magnetic field. The research on biological effect of magnetic field which is conducted according to the magnetic field exposure standard stipulated by ICNIRP and our national magnetic field exposure limit value $(100 \mu \mathrm{T})$ can provide scientific basis for determining the bio-safety threshold, formulating relevant standards and electromagnetic protection and others $^{[6]}$.

\section{Conclusions}

(1) Under intermittent exposure of extremely low frequency magnetic field $(50 \mathrm{~Hz}, 100 \mu \mathrm{T})$, zebrafish embryos develop normally and there was no significant difference between death rate and aberration rate of the exposure group and control group.

(2) Under the above exposure in magnetic field, compared with the control group, there was no significant difference between zebrafish hatching rate of exposure group. This showed that there was no significant influence on embryonic hatch of ELF-MF under exposure.

(3) Heart rate increased steadily and there was no significant difference between treatment groups at 96h of zebrafish embryonic development under magnetic field exposure to extremely low frequency.

(4) In this paper, zebrafish which was model organism was applied as experimental material to study the effect of ELF-MF exposure on embryonic development and provide scientific basis for the formulation of safety limit in power frequency magnetic field.

\section{Acknowledgement}

In this paper, the research was sponsored by the Science-technology Research Foundation of State Grid Corporation of China (GY71-13-057) . 


\section{References}

[1] JanacB, Selakovic V, Raus S, et al. Temporal patterns of extremely low frequency magnetic field-induced motor behavior changes in Mongolian gerbils of different age [J]. International Journal of Radiation Biology, 2012, 88(4): 359-366.

[2] Guideline I. Guidelines for limiting exposure to time-varying electric, magnetic, and electromagnetic fields (up to $300 \mathrm{GHz}$ ) [S]. HealthPhys, 1998, 74(4): 494-522.

[3] Lotfi A, Narimani-Rad M. Effect of exposure to extremely low frequency electromagnetic fields $(50 \mathrm{~Hz}, 0.5 \mathrm{mT})$ during incubation on hatchability, T3 and T4 levels in newly-hatched chicks [J]. Asian Journal of Animal and Veterinary Advances, 2012, 7: 733-738.

[4] Zimmerman S, Zimmerman A M, Winters W D, et al. Influence of $60-\mathrm{Hz}$ magnetic fields on sea urchin development [J]. Bioelectromagnetics, 1990, 11(1): 37-45.

[5] Formicki K, Winnicki A. Reactions of fish embryos and larvae to constant magnetic fields [J]. Italian Journal of Zoology, 1998, 65: 479-482.

[6] Skauli K S, Reitan J B, Walther B T. Hatching in zebrafish (Danio rerio) embryos exposed to a $50 \mathrm{~Hz}$ magnetic field [J]. Bioelectromagnetics, 2000, 21(5): 407-410. 